\title{
REFORMULASI PERENCANAAN PEMBANGUNAN NASIONAL MODEL GARIS-GARIS BESAR HALUAN NEGARA
}

\author{
Ade Kosasih \\ Fakultas Syariah Institut Agama Islam Negeri Bengkulu \\ Jl. Raden Fatah Pagar Dewa Bengkulu \\ Email: adeindrakosasih@iainbengkulu.ac.id
}

\begin{abstract}
The inability of the national long-term development plan (RPJPN) to consolidate different programs between one President and the next President, results in unsustainable development plans. So there is a desire to revitalize the outlines of the state's direction (GBHN) as a guide to national development that was once able to integrate national development planning in the past. Therefore, it is necessary to reform the GBHN, because the concept of GBHN in the past is not necessarily relevant to the current state administration system, especially the implications of the GBHN on the authority of the MPR. The future GBHN systematics will be followed up with the RPJM and the regional midterm development plan (RPJMD) in lieu of the five-year development plan. To strengthen the legality of GBHN as a development planning document, the MPR Decree on GBHN must be interpreted as a fundamental norm, so that if the President deviates from the GBHN, then the President can be impeached. This means that the position and function of the MPR and the Constitutional Court (MK) need to be reconstructed, that is, the MPR is given the authority to submit impeachments and execute MK Decisions related to impeachment of the President in violation of the GBHN, while the Constitutional Court has the authority to examine and adjudicate requests for impeachment. Thus, it is believed that development planning can run in an integrated and sustainable manner.
\end{abstract}

Keywords: Planning; Development, GBHN

\begin{abstract}
Abstrak: Ketidakmampuan rencana pembangunan jangka panjang nasional (RPJPN) mengkonsolidasi programprogram yang berbeda antara Presiden yang satu dengan Presiden berikutnya, mengakibatkan rencana pembangunan tidak berkesinambungan. Sehingga ada keinginan untuk merevitalisasi garis-garis besar haluan negara (GBHN) sebagai pedoman pembangunan nasional yang pernah mampu mengintegrasikan perencanaan pembangunan nasional di masa lalu. Oleh sebab itu, perlu dilakukan reformulasi GBHN, karena belum tentu konsep GBHN di masa lampau masih relevan dengan sistem ketatanegaraan saat ini, terutama implikasi GBHN terhadap kewenangan MPR. Sistematika GBHN d imasa yang akan datang ditindaklanjuti dengan RPJM dan rencana pembangunan jangka menengah daerah (RPJMD) sebagai pengganti rencana pembangunan lima tahun. Untuk memperkuat legalitas GBHN sebagai dokumen perencanaan pembangunan, Tap MPR tentang GBHN haruslah diartikan sebagai staats fundamentalnorm, sehingga jika Presiden menyimpang dari GBHN, maka Presiden dapat di impeachment. Artinya, kedudukan dan fungsi MPR dan Mahkamah Konstitusi (MK) perlu direkonstruksi, yaitu MPR diberi kewenangan untuk mengajukan impeachment dan mengeksekusi Putusan MK terkait impeachment terhadap Presiden yang melanggar GBHN, sedangkan MK berwenang memeriksa dan mengadili permohonan impeachment. Dengan demikian, diyakini perencanaan pembangunan dapat berjalan secara integral dan berkesinambungan
\end{abstract}

Kata kunci: Perencanaan, Pembangunan, GBHN

\section{Pendahuluan}

Saat ini issue untuk kembali menjadikan GarisGaris Besar Haluan Negara (GBHN) sebagai pedoman perencanaan dan penyelenggaraan pembangunan nasional semakin menguat. Salah satu faktor yang melatarbelakangi kondisi tersebut adalah kegagalan RPJPN mengintegrasikan perencanaan pembangunan nasional. Selain itu, RPJPN lebih berbicara pada tataran teknis praktis yang lebih cenderung berperspektif Presiden saja. Sementara konsep filosofis yang bersifat visioner tetapi realistis dan berperspektif multi dimensi 
(dari sudut pandang MPR - DPR \& DPD) tidak tersentuh.

Selama ini RPJPN seolah-olah terstruktur dengan sistematis karena ditindaklanjuti dengan RPJMN, sedangkan di tingkat daerah sebagai derivasi dari RPJPN dan RPJMN dibentuk RPJPD dan RPJMD yang mengacu pada RPJPN. Namun faktanya, sejak awal RPJPN dibentuk pada tahun 2005 yang berlaku selama 20 (dua puluh) tahun, yaitu sampai dengan tahun 2025 pembangunan nasional justru dirasakan mengalami disorientasi. Padahal RPJPN memuat visi Indonesia mandiri, maju, adil dan makmur. Hal tersebut dikarenakan RPJMN merupakan pengejawantahan visi dan misi Presiden, sehingga ketika Presiden berganti, dengan visi dan misi yang berbeda maka terhenti pula pembangunan yang sudah direncanakan dalam RPJMN sebelumnya, dan berganti dengan RPJMN yang baru.

Selain itu, di tingkat daerah disusun RPJPD dan RPJMD yang semestinya mengacu pada RPJPN dan RPJMN. Namun dalam tataran praktik, hal tersebut tidak terintegrasi, mengingat Kepala Daerah belum tentu berasal dari partai yang sama dengan Presiden, atau setidaktidaknya memiliki visi yang sama. Sehingga kemungkinan pengaturan RPJPD dan RPJMD dalam Peraturan Daerah bertentangan dengan Undang-Undang RPJPN dan RPJMN dapat saja terjadi. Adanya peraturan perundangundangan yang tidak harmonis tersebut, tidak menutup kemungkinan akan menimbulkan konflik antara penyelenggara negara, karena undang-undang menyimpan potensi konflik. ${ }^{1}$

Terdapat beberapa ketidakharmonisan dalam sistem perencanan pembangunan saat ini yaitu antara lain: ${ }^{2}$

1 Satjipto Rahardjo, Penyusunan Undang-Undang yang Demokratis, dalam (Jurnal Ilmu Hukum, Universitas Muhammadiyah Surakarta, Vol. 1 No. 2 Tahun II/1998), h. 3.

2 Imam Mahdi, Harmonisasi Pengaturan Hukum Sistem Perencanaan Pembangunan Daerah (Kajian Khusus RPJM Provinsi), (Disertasi Fakultas Hukum Universitas Brawijaya, 2012), h. 137.
1. Disharmoni peraturan perundang-undangan perencanaan pembangunan;

2. Disharmoni antara Undang-Undang tentang Sistem Perencanaan Pembangunan dengan Undang-Undang tentang pemerintahan Daerah;

3. Tidak adanya kewajiban Rencana Kerja Pemerintah Daerah (RKPD) untuk mengacu pada RPJM.

Ketidakmampuan RPJPN mengkonsolidasi program-program yang berbeda antara Presiden yang satu dan Presiden berikutnya mengakibatkan rencana pembangunan tidak berkesinambungan. Berdasarkan latar belakang tersebut, saat ini mulai tumbuh keinginan untuk merevitalisasi GBHN sebagai pedoman dalam penyelenggaraan pemerintahan dan pembangunan nasional. Oleh karena itu, perlu dilakukan reformulasi GBHN, karena belum tentu konsep GBHN di masa lampau masih relevan dengan sistem ketatanegaraan saat ini. Selain itu, kehadiran GBHN pasti berimplikasi pada perubahan terhadap sistem ketatanegaraan Indonesia, salah satu contohnya adalah kehadiran GBHN berpotensi akan mengubah struktur, fungsi, tugas, kewenangan serta hubungan kewenangan antarorgan-organ kenegaraan. Oleh karena itu, perlu dikaji kembali konsep perencanaan pembangunan model GBHN ini agar relevan dengan kondisi kekinian.

\section{Pembahasan}

Pada saat ini, Indonesia mencoba untuk menata negara ini menjadi negara demokrasi dengan membentuk aturan-aturan baru, ${ }^{3}$ diantaranya terkait dengan sistem perencanaan pembangunan nasional. Konsep sistem perencanaan pembangunan yang sedang berlaku saat ini disadari masih terdapat beberapa kelemahan. Sedangkan konsep yang dianggap ideal untuk diberlakukan masih dalam proses perumusan kebijakan. Artinya belum sampai

${ }^{3}$ Ade Kosasih, "Menakar Pemilihan Kepala Daerah Secara Demokratis”, dalam Jurnal Al-Imarah, Vol. 2 No. 1, 2017, h. 40. 
pada tahap pelembagaan. Salah satu yang menjadi issue hangat adalah mengenai keinginan untuk memberlakukan kembali GBHN.

GBHN itu sendiri merupakan landasan nilai paradigma pembangunan di era Orde Baru dan menjadi acuan dari seluruh kebijakan pemerintah. GBHN dan Replita sebagai instrumen utama dari penyelenggaraan pemerintahan Orde Baru sarat dengan konsep dan rencana pembangunan. ${ }^{4} \mathrm{Di}$ dalam GBHN tersebut antara lain diatur pola dasar pembangunan untuk masa waktu 25 (dua puluh lima) tahun, pola umum pembangunan jangka panjang juga untuk masa 25 (dua puluh lima) tahun dan pola umum pelita untuk jangka waktu 5 (lima) tahun. Kemudian Presiden membuat keputusan untuk melaksanakan GBHN tersebut yang dikenal dengan Rencana Pembangunan Lima Tahun (Repelita). ${ }^{5}$

\section{Kajian Filosofis}

Secara normatif landasan idiil perencanaan pembangunan Indonesia adalah Pancasila dan UUD 1945. Secara ideologis sistem perencanaan pembangunan nasional dalam GBHN berorientasi kepada Ketuhanan Yang Maha Esa (berlakunya etik dan moral agama, bukan materialisme); Kemanusiaan yang adil dan beradab (tidak mengenal pemerasan atau eksploitasi); Persatuan Indonesia (berlakunya kebersamaan, asas kekeluargaan, sosio-nasionalisme dan sosiodemokrasi dalam ekonomi); Kerakyatan (mengutamakan kehidupan ekonomi rakyuat dan hajat hidup orang banyak); serta Keadilan Sosial (persamaan/emansipasi, kemakmuran masyarakat yang utama bukan kemakmuran orang-seorang).

Secara konstitusional terjabarkan dalam pokok-pokok pikiran yang meliputi; Pertama, keseluruhan semangat, arah dan gerak pembangunan dilaksanakan sebagai pengamalan

${ }^{4}$ Riyas Rasyid, Otonomi Daerah: Latar Belakang dan Masa Depannya, dalam Syamsudin Haris, Ed. Desentralisasi dan Otonomi Daerah: Desentralisasi, Demokrasi, dan Akuntabilitas Pemerintahan Daerah, (Jakarta: LIPI Press, 2005), h. 6

5 Imam Mahdi, "Reformulasi Sistem Perencanaan Pembangunan Nasional Model Garis-Garis Besar Haluan Negara", dalam Jurnal Al-Imarah Vol. 2, No. 1, 2017, h. 5. dari semua sila Pancasila secara serasi, terutama pengamalan sila keadilan sosial bagi seluruh rakyat Indonesia, yang mengamanahkan agar perekonomian disusun sebagai usaha bersama berdasarkan asas kekeluargaan, cabang-cabang produksi yang penting bagi negara dan mengusasi hajat hidup rakyat banyak dikuasai oleh negara, bumi, air dan kekayaan alam yang terkandung di dalamnya dikuasai oleh negara dan digunakan untuk sebesar-besar kemakmuran rakyat, ${ }^{6}$ sumbersumber kekayaan dan keuangan negara digunakan dengan permusyawaratan lembaga perwakilan rakyat serta pengawasan terhadap kebijakannya ada pada lembaga perwakilan rakyat pula, warga negara memiliki kebebasan dalam memilih pekerjaan yang dikehendaki serta mempunyai hak akan pekerjaan dan penghidupan yang layak, hak milik perorangan diakui dan pemanfaatannya tidak boleh bertentangan dengan kepentingan masyarakat, potensi, inisiatif dan daya kreasi setiap warga negara diperkembangkan sepenuhnya dalam batas yang tidak merugikan kepentingan umum, fakir miskin dan anak terlantar dipelihara oleh negara. ${ }^{7}$

Berdasarkan landasan ideologis dan konstituional tersebut maka sistem perencanaan pembangunan nasional berada pada tiga level filosofis sekaligus; ontologis, epistemologis dan aksiologis. Keberadaan sistem Ekonomi Pancasila sudah ada dengan Pancasila sebagai landasan idealnya dan UUD 1945 sebagai landasan konstitusionalnya. Kedua landasan tersebut lebih lanjut dapat dijabarkan dalam Tap MPR (GBHN) yang merupakan staatsfundamentalnorm. Artinya, kehadiran GBHN sebagai model perencanaan pembangunan nasional masih dapat diterima bahkan masih sangat relevan dengan kondisi kekinian.

\section{Landasan Yuridis}

Perencanaan Pembangunan yang akan dituangkan di dalam GBHN pada prinsipnya

\footnotetext{
${ }^{6}$ Lihat Pasal 33 ayat (1), ayat (2), dan ayat (3) UUD NRI Tahun 1945.

${ }^{7}$ Rumusan Pasal 34 ayat (1) UUD NRI Tahun 1945.
} 
merupakan penegasan berlakunya Pasal 27 (ayat 2), Pasal 33, dan Pasal 34 UUD NRI Tahun 1945. Landasan yuridis normatif ini mengandung tuntunan etik dan moral luhur, yang menempatkan rakyat pada posisi mulianya, rakyat sebagai pemegang kedaulatan, rakyat sebagai ummat yang dimuliakan Tuhan, yang hidup dalam persaudaraan satu sama lain, saling tolong-menolong dan bergotong-royong.

Landasan yuridis yang terkandung dalam Pasal 27 ayat (2) UUD 1945 memberikan tanggung jawab kepada negara untuk memberikan jaminan penghidupan yang layak bagi setiap warga negara Indonesia. Oleh karena itu, negara harus memiliki konsep perencanaan pembangunan yang matang dan terintegrasi secara nasional. Pengalaman masa lalu telah menunjukan keberhasilan GBHN sebagai kerangka acuan pembangunan ekonomi masyarakat.

Landasan yuridis yang terkandung dalam Pasal 33 ayat (3) yang berbunyi, "bumi, air dan kekayaan alam yang terkandung di dalamnya dikuasai oleh negara dan dipergunakan untuk sebesar-besarnya kemakmuran rakyat". Artinya, negara secara sadar menyusun perekonomian secara nasional untuk menghasilkan blue print ekonomi yang akan menjadi petunjuk arah dan pola kebijakan bagi penyelenggaraan serta alat ukur sekaligus jaminan bagi keikutsertaan seluruh rakyat dalam proses produksi bagi tercapainya kesejahteraan rakyat.

Distribusi sumberdaya alam dan seluruh kekayaan negara dilaksanakan oleh pemerintah untuk menjamin kesejahteraan bersama. Berbagai perencanaan yang dilakukan negara adalah; Pertama, melalui penegakan peraturan perundang-undangan. Diantaranya tentang undang-uandang persaingan usaha, hubungan kerja industrial, dan jaminan sosial. Kedua, melalui pelayanan masyarakat. Diantaranya pelaksanaan undang-undang pelayanan publik, dan undang-undang keterbukaan informasi publik. Ketiga, melalui instrumen fiskal. Diantaranya penghapusan pajak, pemberian subsidi serta pembuatan prasarana dan sarana yang langsung berhubungan dengan rakyat seperti jalan dan irigasi. Keempat, pembentukan dan penguatan BUMN.

\section{Landasan Sosiologis}

Sistem perencanaan pembangunan nasional akan lebih mencerminkan kehendak seluruh rakyat Indonesia jika dituangkan dalam GBHN yang ditetapkan dengan Tap MPR. $\mathrm{Hal}$ ini mengingat MPR merupakan forum yang mencerminkan keterwakilan politik yang terjelma dalam DPR dan keterwakilan wilayah yang terjelma dalam DPD, oleh karena walaupun MPR bukan lagi lembaga tertinggi negara, namun jika GBHN ditetapkan oleh MPR, maka masih relevan jika dikatakan MPR adalah merupakan pemegang kekuasaan rakyat secara konstitusional.

"Rakyat" di sini adalah pengertian rakyat dalam konsepsi politik, bukan konsepsi aritmatik atau statistik, rakyat tidak harus berarti seluruh penduduk. Rakyat adalah "the common people", rakyat adalah "orang banyak". Pengertian rakyat di sini berkaitan dengan "kepentingan publik", yang berbeda dengan "kepentingan orangseorang”. Pengertian rakyat mempunyai kaitan dengan kepentingan kolektif atau kepentingan bersama. Istilah "rakyat" memiliki relevansi dengan hal-hal yang bersifat "publik" itu.

\section{Bentuk Hukum GBHN}

Jika face back pada era Orde Baru, MPR adalah lembaga tertinggi negara yang memegang kedaulatan rakyat yang salah satunya adalah memilih dan mengangkat Presiden dan Wakil Presiden dan menetapkan GBHN. Presiden yang diangkat oleh Majelis tunduk dan bertanggungjawab kepada Majelis. Ia adalah "mandataris" dari Majelis dan wajib menjalankan putusan-putusan Majelis, ${ }^{8}$ sehingga GBHN dianggap sebagai penjelmaan kehendak seluruh

${ }^{8}$ Bagir Manan, Lembaga Kepresidenan, (Yogyakarta: UII Press, 1999), h. 37. Lihat pula Bagir Manan, Teori dan Politik Konstitusi, (Yogyakarta: UII Press, 2003), h. 17. 
rakyat Indonesia, ${ }^{9}$ karena itu Presiden berada di bawah MPR, menjalankan haluan negara yang ditetapkan MPR. Presiden menurut Soepomo, sebagaimana dikutip Jimly Asshiddiqie, tidak boleh mempunyai politik sendiri, tetapi harus menjalankan haluan negara yang ditetapkan, diperintahkan oleh MPR. ${ }^{10}$

GBHN tersebut kemudian menjadi pedoman Presiden sebagai mandataris MPR dalam menyelenggarakan pemerintahan dan pembangunan. Konsekuensinya adalah jika Presiden keluar dari GBHN maka MPR dapat menyatakan mosi tidak percaya kepada Presiden dan mencabut mandatnya. Dengan kata lain, MPR dapat memberhentikan Presiden. Kewenangan MPR memberhentikan Presiden ini tidak terlepas dari sistem Pemilu tidak langsung, yaitu Presiden dipilih oleh MPR dan secara contrario MPR pun berwenang memberhentikan Presiden.

Mengingat MPR saat ini tidak memiliki kewenangan untuk menetapkan GBHN lagi seperti era UUD 1945 sebelum amandemen, maka jika GBHN akan dihidupkan kembali, berarti MPR akan memiliki kewenangan menetapkan GBHN kembali. Implikasi lebih lanjut, jika Presiden menyimpang dari GBHN maka MPR dapat memberhentikan Presiden. Akan menjadi permasalahan jika ternyata rakyat masih menginginkan Presiden dipilih secara langsung bukan dipilih oleh MPR. Sehingga tidak rasional jika MPR memberhentikan Presiden yang dipilih langsung oleh rakyat. Oleh karena itu, perlu dikaji lebih mendalam mengingat konstalasi politik, arena dan struktur politik telah berubah. Sekarang ini perbedaan penafsiran terhadap konsep-konsep negara tidak mudah diatasi, karena paradigma berpikir terarah kepada kebebasan, sementara rencana menghidupkan kembaliGBHN akan berdampak pada perubahan struktur ketatanegaraan termasuk berimbas pada sistem Pemilu dan

${ }^{9}$ Lihat Pasal 3 UUD 1945

${ }^{10}$ Jimly Asshiddiqie, Hukum Tata Negara dan Pilar-Pilar Demokrasi, (Jakarta: Konstitusi Press, 2005), h. 17. mekanisme dan alasan pemberhentian Presiden apakah alasan hukum atau alasan politik.

Alternatif lain jika masih menginginkan pemilihan Presiden secara langsung oleh rakyat, maka model perencanaan pembangunan harus tetap dibentuk dan ditetapkan oleh MPR, walaupun dalam konteks pemisahan kekuasaan (sparation of power) kedudukan MPR sederajat dengan Presiden. Namun, untuk memperkuat legalitas GBHN sebagai dokumen perencanaan pembangunan Tap MPR tentang GBHN tersebut haruslah diartikan sebagai staats fundamentalnorm, sehingga jika Presiden menyimpang dari GBHN maka Presiden tersebut telah menyimpang dari staats fundamentalnorm yang notabene norma hukumnya sama dengan konstitusi. Itu artinya Presiden dapat di impeach atas dasar melanggar GBHN dengan mekanisme MPR sebagai pemohon impeachment Presiden ke Mahkamah Konstitusi untuk diperiksa dan diadili. Jika permohonan impeacment tersebut terbukti dan dikabulkan, maka Presiden dapat diberhentikan.

Kewenangan MPR untuk menetapkan GBHN merupakan alasan yang paling rasional, karena jika kewenangan menetapkan GBHN diberikan kepada DPR, maka tidak akan jauh berbeda nasibnya dengan RPJP saat ini yang merupakan kristalisasi visi dan misi serta plaform partai politik yang berada di DPR, dengan keterbatasan berbagai kelemahan dan keterbatasannya. Di sisi lain, DPR bukanlah merupakan penjelmaan kehendak seluruh rakyat melainkan wakil Parpol di parlemen. Artinya dibutuhkan keterwakilan rakyat secara langsung yang tercermin dalam DPD. Namun, juga tidak tepat jika kewenangan menetapkan GBHN diberikan kepada DPD, karena keterwakilan Parpol tidak terakomodir. Oleh karena itu, akan lebih tepat jika kewenangan menetapkan GBHN terletak di tangan MPR yang merupakan lembaga afiliasi antara DPR dan DPD. Sehingga keterwakilan rakyat dan Parpol dapat diakomodir. Konsekuensinya, perlu dilakukan Amandemen Kelima UUD 1945 dalam rangka 
mengembalikan kewenangan MPR menetapkan GBHN.

Secara singkat telah tergambar implikasi GBHN terhadap perubahan kewenangan organ-organ kenegaraan, khususnya MPR yang memperoleh kembali kewenangan menetapkan GBHN. Di samping itu, keterbatasan fungsifungsi DPD dalam hubungannya dengan DPR dalam sistem parlemen akan dapat direduksi dengan peran strategis DPD sebagai anggota MPR yang berwenang menetapkan GBHN. Dengan demikian, kedudukan DPD dalam MPR akan menjadi counterpart DPR yang diharapkan mampu menjadi pengimbang dan mengurangi arogansi DPR dalam parlemen (MPR). Di samping itu, selain fungsi dan peran DPD yang menguat, fungsi dan peran MPR pun semakin strategis karena mengalami penambahan kewenangan.

Jika kewenangan menetapkan GBHN dimiliki kembali oleh MPR, maka GBHN tersebut akan dituangkan dalam produk hukum yang berbentuk Ketetapan MPR (Tap-MPR). Artinya, kewenangan MPR dalam membentuk Tap-MPR secara otomatis akan dipulihkan kembali. Di samping itu, kedudukan Tap-MPR dalam hierarki peraturan perundang-undangan akan semakin jelas eksistensinya. Selama ini kedudukan Tap-MPR di satu sisi masih diakui, walaupun hanya tinggal 14 buah lagi. Namun di sisi lain MPR tidak berwenang lagi membentuk Tap MPR yang baru. Dengan adanya GBHN ini, maka akan ada lagi Tap MPR yang baru.

Selain itu, adanya Tap MPR tentang GBHN harus disertai dengan mekanisme pengawasan terhadap peraturan pelaksanaanya, yang dalam hal ini Undang-Undang tentang RPJM Nasional. Dengan kata lain, jika UndangUndang tentang RPJM Nasional yang nota bene adalah peraturan pelaksana dari Tap MPR tentang GBHN bertentangan dengan Tap MPR tentang GBHN, maka dibutuhkan mekanisme kontrol yuridis terhadap undang-undang tersebut. Mekanisme kontrol yuridis tersebut tidak lain adalah melalui hak menguji (toetsing recht) melalui judicial review yang diberikan kepada Mahkamah Konstitusi, sehingga secara tidak langsung berimplikasi pada semakin menguatnya fungsi MK. Hal ini dikarenakan selama ini MK hanya berwenang menguji undang-undang terhadap UUD, sedangkan jika undang-undang bertentangan dengan Tap MPR, maka undang-undang tersebut tidak dapat diuji, akibatnya harmonisasi hukum yang diharapkan sulit terwujud.

GBHN sebagai manifesto politik yang memuat grand design konsep pembangunan harus mampu menjawab tantangan di masa yang akan datang. Sebagai konsep besar pembangunan nasional yang memayungi seluruh konsep visi dan misi Presiden, maka dibutuhkan instrumen pelaksananya. Wujud instrumen pelaksana tersebut dapat mempertahankan konsep yang sudah ada, yaitu RPJM atau kembali dengan nama lama di era Orde Baru, yaitu Rencana Pembangunan Lima Tahun (Replita). Jika GBHN dituangkan dalam Tap MPR, maka instrumen pelaksananya RPJM Nasional dituangkan dalam undang-undang sebagai peraturan di bawah Tap MPR. Sedangkan derivasinya untuk tingkat daerah adalah RPJM Daerah yang dituangkan dalam Peraturan Daerah (Perda). Konsekuensi adanya GBHN, maka tidak diperlukan lagi RPJP, karena GBHN inilah yang akan menggantikan peran dan funsgi RPJP.

Korelasi yang erat antara MPR dan GBHN membentuk legitimasi demokrasi yang kuat dan utuh, mengingat GBHN dibentuk oleh MPR yang nota bene MPR tidak dapat disebut hanya sebagai "joint session" antara DPR dan DPD, ${ }^{11}$ sehingga GBHN menjadi garis kebijaksanaan dalam perencanaan pembangunan nasional sesuai dengan cita-cita dan asas kerohanian bangsa. ${ }^{12}$ Selain itu, GBHN mencerminkan keterwakilan kehendak seluruh rakyat Indonesia dan mampu mengakomodir serta meng-

${ }^{11}$ Ade Kosasih dan Imam Mahdi, Hubungan Kewenangan Antara DPD dan DPR dalam Sistem Parlemen Bikameral, (Bengkulu: Penerbit Vanda, 2016), h. 11.

${ }_{12}$ Ramdlonnaning T.T., Cita dan Citra Hak Asasi Manusia di Indonesia, (Jakarta: Lembaga Kriminologi UI, 1983), h. 83. 
konsolidasikan visi dan misi pembangunan yang berbeda antara Presiden yang satu dengan Presiden berikutnya secara berkesinambungan, konsep rencana pembangunan dalam GBHN juga lebih stabil dan terarah. Dikatakan stabil, karena GBHN dituangkan dalam Tap MPR, sehingga lebih sulit untuk diubah, sekalipun terjadi transisi kepemimpinan jika dibandingkan dengan RPJP/RPJM yang dituangkan dalam undang-undang. Dikatakan terarah, GBHN menjadi pedoman rencana pembangunan, sehingga sejak awal Calon Presiden tidak dibenarkan memiliki visi dan misi yang berbeda dengan GBHN. Konsekuensi lebih lanjut, RPJM harus mempedomani GBHN. Dikatakan terarah, GBHN menjadi standar baku program pembangunan yang bersifat tetap dalam jangka waktu panjang, yang dilaksanakan secara bertahap dan terukur oleh RPJM/Replita.

Dilihat dalam konteks perencanaan strategis, apa-apa yang telah dicantumkan di dalam GBHN sudah begitu kuat untuk memandu dan menjadi haluan pembangunan nasional yang berkelanjutan. Hal ini karena setidaknya GBHN mengandung beberapa hal yang mendasar diantaranya adalah: 1) dasar dan landasan filosofis sekaligus penjelasannya sehingga dapat menjadi "tali kendali" yang selalu melekat pada setiap langkah pembangunan bangsa. Tali kendali ini penting karena tidak ada artinya pembangunan dan hasilnya manakala dia lepas dari filosofi dasar bernegara dan abai terhadap nilai dan ruh Pancasila sebagai dasar dan ideologi negara; 2) GBHN memuat wawasan nusantara dimana didalamnya berisi tentang cara pandang tentang bangsa Indonesia terhadap dirinya dan lingkungan strtegis yang melingkupinya. Hal ini penting untuk dapat membantu mengidentifikasi dan menganalisis potensi kekuatan, kelemahan, peluang, maupun ancaman yang ada sehingga dapat ditangani dengan tepat. Keberadaan wawasan nusantara sebagai suatu dokumen yang tidak terpisahkan dengan perencanaan pembangunan adalah suatu hal yang mutlak untuk dikuatkan karena akan sangat membantu mewujudkan perencanaan pembangunan yang telah ditentukan; 3) GBHN menegaskan pentahapan-pentahapan yang harus dicapai lengkap dengan indikator pencapaian program pembangunan. Hal ini tentulah sangat baik karena memberikan "time line" sekaligus ramburambu waktu yang diperlukan. ${ }^{13}$

\section{Penutup}

Dari uraian di atas, dapat disimpulkan sebagai berikut:

a. GBHN sangat relevan dengan kondisi kekinian, yang mengalami disorientasi pembangunan. Sikap skeptis sebagian masyarakat akan kembali pada sistem Pemilu Presiden secara tidak langsung jika GBHN diberlakukan kembali, sesungguhnya tidak memiliki relevansi dan korelasi dengan sistem Pemilu.

b. Organ yang menetapkan GBHN diberikan kembali kepada MPR sebagai lembaga afiliasi DPR dan DPD.

c. Kehadiran GBHN berimplikasi pada perubahan sistem ketatanegaraan, khususnya terhadap fungsi MPR, DPD, dan MK.

d. Sistematika GBHN diikuti dengan RPJM dan RPJMD.

e. GBHN memiliki kemampuan mengkonsolidasikan dan mengakomodir kepentingan yang berbeda serta lebih stabil dan terarah jika dibandingkan dengan RPJP.

Oleh sebab itu, ada beberapa saran sebagai rekomendasi:

a. Sebaiknya reformulasi GBHN sebagai manifesto politik yang menjadi pedoman pembangunan tidak ditunggangi oleh kepentingan untuk kembali pada UUD 1945 yang lama, melainkan upaya tambal sulam UUD NRI Tahun 1945 agar lebih ideal dengan tuntutan demokrasi.

b. Sebaiknya langkah kembali memberlakukan

${ }^{13}$ Endang Maria Astuti, Garis-Garis Besar Haluan Negara, Perencanaan Strategis dan Kepemimpinan Transformasional, www. budayabangsa.com, diakses pada tanggal 7 Oktober 2016. 
GBHN bukan sekedar menyusun naskah manifesto politik, namun sebagai langkah mewujudkan perilaku politik yang konsisten, stabil, terarah, dan efektif dalam semangat demokrasi.

\section{Pustaka Acuan}

Asshiddiqie, Jimly. Hukum Tata Negara dan Pilar-Pilar Demokrasi, Jakarta: Konstitusi Press, 2005.

Asshiddiqie, Jimly. Sengketa Kewenangan Lambaga Antarnegara, Jakarta: Konstitusi Press, 2005.

Astuti, Endang Maria. Garis-Garis Besar Haluan Negara, Perencanaan Strategis dan Kepemimpinan Transformasional, www. budayabangsa.com, diakses pada tanggal 7 Oktober 2016.

Firdaus, Pertanggungjawaban Presiden dalam Negara Hukum Demokrasi, Bandung: Yrama Widya, 2007.

Kosasih, Ade, dan Imam Mahdi. Hubungan Kewenangan Antara DPD dan DPR dalam Sistem Parlemen Bikameral, Bengkulu: Penerbit Vanda, 2016.

Kosasih, Ade. "Menakar Pemilihan Kepala Daerah Secara Demokratis", Jurnal AlImarah, Vol. 2, No. 1, 2017.
Mahdi, Imam. "Harmonisasi Pengaturan Hukum Sistem Perencanaan Pembangunan Daerah (Kajian Khusus RPJM Provinsi)", Disertasi Fakultas Hukum Universitas Brawijaya, 2012.

Mahdi, Imam. "Reformulasi Sistem Perencanaan Pembangunan Nasional Model Garis-Garis Besar Haluan Negara", Jurnal Al-Imarah, Vol. 2, No. 1, 2017.

Manan, Bagir. Lembaga Kepresidenan, Yogyakarta: UII Press, 1999.

Manan, Bagir. Teori dan Politik Konstitusi, Yogyakarta: UII Press, 2003.

Rahardjo, Satjipto. "Penyusunan Undang-Undang yang Demokratis", Jurnal Ilmu Hukum, Universitas Muhammadiyah Surakarta, Vol. 1 No. 2 Tahun II/1998.

Rasyid, Riyas. Otonomi Daerah: Latar Belakang dan Masa Depannya, dalam Syamsudin Haris, Ed. Desentralisasi dan Otonomi Daerah: Desentralisasi, Demokrasi, dan Akuntabilitas Pemerintahan Daerah, Jakarta: LIPI Press, 2005.

T.T, Ramdlonnaning. Cita dan Citra Hak Asasi Manusia di Indonesia, Jakarta: Lembaga Kriminologi UI, 1983. 